\title{
Competition for floral resources drives the differentiation of foraging strategy among three dominant bumble bees in an eastern Himalayan meadow
}

\author{
Zhongming $\mathrm{YE}^{1}$, David Inouye ${ }^{2}$, Xiao-Fang Jin $^{3}$, Jian Yang ${ }^{1}$, Han-Ning Lun ${ }^{1}$, qingfeng \\ wang $^{1}$, and Chun-Feng Yang ${ }^{1}$ \\ ${ }^{1}$ Wuhan Botanical Garden, Chinese Academy of Sciences \\ ${ }^{2}$ The Rocky Mountain Biological Laboratory \\ ${ }^{3}$ Institute of Zoology Chinese Academy of Sciences
}

May 5, 2020

\begin{abstract}
An understanding of the influence of competition on bumble bees' foraging strategy is essential to understand the coexistence of multiple bee species in the context of pollinator declines, but remains unclear. We conducted a field survey in an isolated meadow in eastern Himalaya with10 bumble bee species and more than 55 flowering plants they visited. In 2018 and 2019 we measured abundance of the three dominant bumble bees (one mainly foraging for pollen and two for nectar) and recorded the identity and frequency of flowering plants they visited. The intensity of competition of species pairs was evaluated by niche overlap. A composite index of flower depth of plants visited by each bumble bee was calculated on each sampling day. Results indicated that foraging strategies of the three bee species shifted differentially in response to increasing competition; the pollen-seeking bee was forced to forage for more nectar while the nectar-seeking bees were impelled to change target flowers in order to match proboscis length and flower depth. The coexistence of multiple bumble bee species in a community can thus be achieved by adjusting foraging strategy in response to intensity of competition for floral resources.
\end{abstract}

\section{Keywords}

Bumble bee, Bombus, coexistence, competition intensity, floral resources, foraging strategy, niche differentiation, niche overlap, pollinator, proboscis length.

\section{Introduction}

As one of the most valuable pollinators, bumble bees are vitally important to productivity for both natural and agricultural systems (Hegland \& Totland, 2008; Garratt et al., 2014). They are distributed world-wide in temperate climates (Williams \& Osborne, 2009). An increasing number of papers have suggested that high priority should be given to their conservation due to the serious risk of declines (Goulson et al., 2008a, 2015; Williams et al., 2009; Roulston \& Goodell, 2011). A main cause for bumble bee decline is the decrease of floral resources (Roulston \& Goodell, 2011; Goulson et al., 2015; Thomson, 2016); there is strong evidence that floral resources significantly influence abundance of bumble bees (reviewed in Roulston \& Goodell, 2011 and Goulson et al., 2015) and that responses to floral resources can be species-specific (Ogilvie et al., 2017). However, the interspecific interactions of bee species in response to changing floral resources still need to be explored, as they are fundamental for understanding the patterns and mechanisms of bee decline in this changing world (Thomson, 2016).

It was suggested that two or more bumble bee species coexisting in a plant community may have to obey rules for partitioning the limited floral resources through competitive interactions (Inouye, 1978; Heinrich, 
1976; Ranta \& Lundberg, 1980), and niche differentiation in bumble bee proboscis length and flower use could be be an effective way of partitioning resources (Heinrich, 1976; Inouye, 1980; Pyke, 1982). Matching of proboscis length and flower depth was identified as a key component for the resource partitioning among bumble bee species (Inouye, 1977; Ranta et al., 1981; Pyke, 1982). Therefore, differences in proboscis length may influence niche relations and community structure for bumble bee species (Ranta \& Vepsalainen, 1981; Pyke, 1982; Pyke et al., 2012). On this basis, a classic hypothesis was postulated that coexistence would be difficult for bumble bee species with similar proboscis length in a community (Inouye, 1977, 1978, 1980; Pyke, 1982; Ishii et al., 2008). However, studies also indicated that the structure of bumble bees may also depend on the community's temporal and spatial factors rather than niche differentiation in proboscis length and flower use (Ranta \& Lundberg, 1980; Ranta \& Vepsalainen, 1981; Pyke et al., 2012; Miller-Struttmann \& Galen, 2014). However, studies revealed that multiple bumble bee species with similar proboscis length can coexist in a community with few differences in their abundance (Ranta, 1982, 1984; Ranta \& Tiainen, 1982; Williams, 1989; Goulson \& Darvill, 2004). This indicated that the interspecific interactions within a community of bumble bees are more complex than previously thought.

The intensity of interspecific competition among bumble bee species was thought to be highly environmentdependent (Ranta \& Lundberg, 1980). For example, Ranta et al. (1981) showed that the niche overlaps of the bumble bees were smaller in a northern (unstable environment) than in the southern community (more stable environment) in Fennoscandinavia. Moreover, the foraging strategy of bumble bees displayed a high level of plasticity in response to changes in landscape factors and floral resource diversity (Jha \& Kremen, 2013). However, whether and how interspecific competition influences the foraging strategy of bumble bees in a scenario of changing floral resources remains unclear, but is fundamental for understanding the coexistence of multiple bumble bee species. Thus it may be important to incorporate a phenological component to study of their resource use, as abundance of bees in the annual colonies changes markedly during the course of the summer.

Nutritional requirement was proved to be a key force in shaping foraging strategy and floral preference for bumble bees (Vaudo et al., 2016), which is not surprising given the impact of diet on their colony health (Roger et al., 2017). Different bumble bee species may vary in nutritional requirements, which would force them to prefer different plant species for comprehensive nutrition intake (Pyke, 1982; Goulson et al., 2005; Hanley et al., 2008; Moerman et al., 2016; Woodard, 2017). Given that pollen and nectar of flowering plants provide different nutrients for pollinators (reviewed in Baker \& Baker, 1983; Roulston \& Cane, 2000), bumble bees may differ in preference for pollen or nectar, and thus preferentially forage on different plants since some plants do not provide nectar (Konzmann \& Lunau, 2014). For the bumble bees that forage preferentially for pollen rather than nectar, niche differentiation in proboscis length and flower use may not be important in partitioning of floral resources, although such mechanisms are not well studied. Detecting the influence of intensity of interspecific competition for floral resources on foraging strategy of mainly pollen-seeking bumble bees should provide a good perspective to understand their community structure.

In this study, we hypothesized that the intensity of interspecific competition may influence foraging strategy of bumble bees. On one hand, the niche differentiation in proboscis length and flower use might not be stationary, but depend on the degree of competition. Alternatively, the foraging preference for pollen or nectar might also be plastic when coexisting species reduce the available floral resources. To understand better the factors influencing community structure and the coexistence of bumble bees with similar proboscis lengths, it is necessary to consider study sites where the level of spatiotemporal variability is minimal, or sites are sufficiently isolated that immigration should not be significant (Pyke et al., 2012). To test the hypothesis, we conducted field investigations on a relatively isolated alpine meadow in the eastern Himalayan of Yunnan Province, China, a world top biodiversity hotspot. Three Bombus species, namely, B. friseanus, B. lepidus and B. festivus were the most abundant species, and their proboscis lengths (workers and males) vary from about 6 to $10 \mathrm{~mm}$. Specifically, the main objectives of the study are: (i). what is the pattern of partitioning of floral resources by the three bumble bees? (ii). whether and how the niche differentiation in proboscis length and flower use is influenced by intensity of interspecific competition for the three bumble bees; and (iii). whether and how the intensity of interspecific competition influences foraging preference between pollen 
and nectar for the three bumble bees.

\section{Methods}

\section{Study area}

The field survey was conducted in an alpine meadow located in Shangri-La County $\left(27^{\circ} 37^{\prime} 40^{\prime \prime}\right.$ N, $99^{\circ} 47^{\prime} 32^{\prime \prime}$ E; 3379 m), Northwest of Yunnan Province, China. The study area was about 12 hectares, which was a small valley basin surrounded by mountains. For the pollinators, the study site could be regarded as an isolated area because the mountains were mainly covered by coniferous forests and the nearest meadows were $2 \mathrm{~km}$ away (straight-line distance) and separated by the forests. More than 120 flowering plant species grow in the meadow, including more than 55 plant species visited by bumble bees. The flowering season extends from May to September. The most dominant plant is Polygonum macrophyllum D. Don., which contributes to no less than $40 \%$ of the coverage for this meadow. The next most dominant species areSanguisorba filiformis (Hook. f.) Hand. -Mazz., Anemone obtusiloba D. Don., Pedicularis densispica Franch.,Phlomis atropurpurea Dunn. etc.

\section{Census of flower-visiting bumble bees}

Bumble bees were collected in the site for two summers, 2018 and 2019. We conducted 15 surveys at five- or six-days intervals for the two years, 5 times in July in 2018 and 10 times from July to August in 2019. Each survey was conducted on transects $(50 \mathrm{~m}$ in length and $2 \mathrm{~m}$ in width) selected for sampling floral resources and their visiting bumble bees across the flowering season; transects were located to include a representative diversity and abundance of floral resources, and used again until there were no flowers in it. New transects were added to the field survey as floral resources changed in the meadow, and at peak flowering there were about 20 transects. From 0930 to $1630 \mathrm{H}$ on a warm and dry day favorable to bee activity, we recorded the bumble bees that were visiting flowers by walking along the transects at constant speed for a period of about 10 minutes. On each survey day we completed between 10 and 22 transects according to the abundance and diversity in floral resources at the meadow (see Table S3 for details). Sampling involved collecting all bumble bees with sweep nets, and then the bees were cooled in an ice chest to slow their movement for identification with a hand lens. The abundance of each bumble bee species was calculated as the number per transect. Each bumble bee was identified to species and social caste (queen, worker, male; only 1-2 queens per species were seen). The bees were released after being identified except for those that could not be identified easily in the field, which were stored in centrifuge tubes $(5 \mathrm{ml})$ and later pinned to take to the laboratory for identification. For those bees with similar color stripes, the DNA was extracted from a middle leg stored in $100 \%$ pure ethanol for identification by COI barcoding (Huang et al., 2015). Proboscis length (the total length of prementum and glossa) was measured with a vernier caliper when the specimens were fresh. All specimens were deposited in the Wuhan Botanical Garden, Chinese Academy of Sciences.

We also recorded the identity of plant species for each visit when its flowers were visited by the bumble bees. Several traits were measured for all the involved flowering plants, e.g. nectar or nectarless, tubular or non-tubular, and the corolla depth for a tubular flower. Depending on the reward of the flowering plant, the bumble bees were classified as nectar collectors when they visited a flower providing nectar (although they may have also collected pollen from the flower) and pollen collectors when they visited a nectarless flower. In fact, the pollen collectors only visited five species of Pedicularis, which provided pollen as the only reward for bumble bees in this meadow. Flower depth referred to the distance from the base of the nectary to the base of the corolla limb, which was measured on fresh and fully open flowers $(\mathrm{N}=10)$ to the nearest 0.01 mm with a vernier caliper.

\section{Data analysis}

Based on the total bumble bee counts (for which all castes were pooled), our analyses focused on the three most common species: Bombus lepidus , B. friseanus, and B. festivus. The reason for using data for all castes combined was to provide an overall measure of dietary similarity among species. To quantify the effects of temporal variability and availability of floral resources, the data were collected on each of the sampling 
dates. On a sampling day, the abundance of each bumble bee species was recorded by the accumulated numbers of visits for the species from all transects and averaged to a single transect level. To quantify use of the available resources, the accumulated numbers of a flowering plant visited by a bumble bee species were also noted from all the sampled transects on the day. For each of the bumble bee species, the proportion of nectar collectors out of all recorded visits was also calculated on each sampling day.

In this study, we aimed to find the pattern of the partitioning for floral resources among the three bees, and the temporal dynamic of the pattern, and moreover, the influence of availability of floral resources on the shift in foraging strategy of the bees. For the partitioning of floral resources among the three bees, we first compared the bee abundance on each sampling day through the flowering season of the community. Second, we analyzed the differences in plants visited by each of the bumble bee species between species pairs for the three bees in 2018 and 2019. The resource use of each bumble bee species in a year included the flower identity and the total number of visits; a paired t-test was used to detect the difference in plant composition between species pairs under IBM SPSS 22 (IBM Corp, 2013). We also calculated the relative frequency of a bee on a flowering plant on a sampling day. The top 15 plants that received most visits by the bees were investigated. The relative visiting frequency refers to the proportion of the number of visits for a plant out of the total number of visits on all plants for a bee on a sampling day. To detect the influence of availability of floral resources on foraging strategy of the bees, we investigated the intensity of interspecific competition for floral resources on plant preference.

The flower diversity and availability of floral resources may vary temporally, as does the abundance of bees, thereby creating different levels of intensity of interspecific competition throughout the flowering season. The overlap of floral-resource usage between bumble bee species has been used widely to evaluate the intensity of interspecific competition among bees in a community (Goulson et al., 2008b; Nishikawa \& Shimamura, 2016). In this study, this measure of niche overlap was also applied to quantify the competition intensity among the three bumble bee species for floral resources across the different sampling dates. We used the measure of intensity of competition between species pairs was that proposed by Colwell and Futuyma (1971). The niche overlap between bumble bee species $\mathrm{i}$ and $\mathrm{h}$ was calculated by the formula:

$1-1 / 2 \sum_{k}\left|P_{\mathrm{ik}}-P_{\mathrm{hk}}\right|$

where

$$
P_{\mathrm{ik}}=\frac{\text { Individuals of species i visting plant species } \mathrm{k}}{\text { Total individuals of species } \mathrm{i}}
$$

To detect the plant preference of a bumble bee in response to changes in competition intensity, we analyzed the relationship between the values of niche overlap and those of the proportion of nectar collectors out of total visitors for each of the bumble bee species. In addition, the relationship between abundance of each bumble bee and its niche overlap with the other bees was quantified by the Pearson correlation under IBM SPSS 22 (IBM Corp, 2013).

Niche differentiation in proboscis length and flower use is thought to play an important role in partitioning of floral resources among bumble bees (Heinrich, 1976; Inouye, 1980; Pyke, 1982). However, such a correlation could be complicated because of the temporal and spatial variations in identity and availability of floral resources (Pyke et al., 2012; Miller-Struttmann \& Galen, 2014). A bumble bee may visit a wide range of plant species with varied floral depth (see also Ranta \& Lundberg, 1980). To show better the foraging preference for flowers with different traits for a bumble bee, we developed an index of composite flower depth. On each sampling day, all the flowers visited by one bumble bee species collectively formed a composite flower depth, which was calculated as follows:

Composite flower depth $=x_{1} f_{1}+x_{2} f_{2}+\ldots+x_{k} f_{k}$

Where, $\mathrm{x}_{\mathrm{k}}$ means the flower depth of species $\mathrm{k} ; \mathrm{f}_{\mathrm{k}}$ represents the percentage of visits received by plant species $\mathrm{k}$ out of the total visits made by bumble bee species on a sampling day. The plants with nectarless flowers 
were excluded in calculation of composite flower depth. To detect the influence of intensity of interspecific competition for floral resources on foraging strategy of bumble bees, we analyzed the relationship between the niche overlap and composite flower depth for each of the bumble bee species by using Pearson correlation under IBM SPSS 22 (IBM Corp, 2013).

\section{Results}

A total of 1356 individual bumble bees belonging to 10 different species were recorded in the meadow during the two years (Table S1).Bombus lepidus, B. friseanus and B. festivus, the most abundant species, represented $32.22 \%, 44.25 \%$ and $13.42 \%$ of the total individuals, respectively. The proportion of pollen collectors out of all visits recorded in the two years was $7.95 \%, 14.65 \%$ and $56.13 \%$ for B. lepidus, B. friseanus and B. festivus, respectively. In addition, the length of proboscis for workers of B. lepidus, B. friseanus and B. festivus was $6.46 \pm 0.08 \mathrm{~mm}, 8.07 \pm 0.08 \mathrm{~mm}$, and $9.52 \pm 0.19 \mathrm{~mm}$, respectively (Table S1). The two bumble bees with higher abundance, B. lepidus and B. friseanus, differed by about 10 days in peak of abundance (Fig. 1).

In total, 55 flowering plant species were visited by the three bumble bee species (Table S2). Bombus friseanus , B. lepidus and B. festivus visited 29, 33, and 24 species, respectively (Table S2). Flowers of the most dominant species, Polygonum macrophyllum, attracted the most visits among all of the flowering plants for the two mainly nectar-seeking bumble bee species, B. lepidus and B. friseanus . B. lepidus visitedGeranium refractum second most often, followed by Trollius farreri, while B. friseanus, visited Phlomis atropurpureaand Pedicularis densispica in sequence. For the mainly pollen-seeking bee, B. festivus, the foraging preference wasPedicularis cephalantha followed by P. rhinanthoides(Table S2; see also Table S3). The flower preferences of the bumble bees did not significantly differ in all of the species pairs in the two years even though the number of visits of the bees varied in the two years (Table 1). Moreover, for each of the bumble bees, the relative frequency of visits to a plant varied highly across the sampling dates (Table S3).

The niche overlaps between species pairs of the three bumble bee species varied widely across the sampling dates (Table 2). Moreover, Pearson correlation analysis indicated that the abundance of each bee species (primarily workers, with relatively few males, and the four queens were not included) was not correlated with the value of niche overlap between species pairs for all the three bees (Fig. 2).

Our results indicated that the bee abundance, the proportion of nectar collectors out of total visits by a bee species, and the composite flower depth of plants visited by a bee species varied widely across the sampling dates (Table 3). Moreover, for B. festivus, the mainly pollen-seeking bee with the lowest abundance, the proportion of nectar collectors out of all recorded visits was positively correlated with its niche overlap to bothB. lepidus $(\mathrm{R}=0.67, \mathrm{P}=0.007)$ and B. friseanu $(\mathrm{R}=0.83, \mathrm{P}=0.001$; Fig. 3). For the other two mainly nectar-seeking bees with higher abundance, B. lepidus and B. friseanus, we failed to find a significant relationship between niche overlap and foraging preference of nectar vs. pollen. Furthermore, the niche overlap between these two species was positively correlated with the composite flower depth of plants visited by $B$. lepidus $(\mathrm{R}=0.60, \mathrm{P}=0.039$; Fig. 4$)$, but negatively correlated with the composite flower depth of plants visited by $B$. friseanus $(\mathrm{R}=0.898, \mathrm{P}<0.001$; Fig. 4$)$. However, for $B$. festivus, there was no significant relationship between niche overlap and composite flower depth of plants visited by the mainly pollen-seeking bee.

\section{Discussion}

\section{Partitioning of floral resources by the three dominant bees}

Three components may contribute to form the niche of a bumble bee, namely, nesting site, foraging preferences on flower type, and emergence time (Schoener, 1974). We don't have information about nest sites (likely all subterranean) for the species we studied, but have investigated the other two components. For the two mainly nectar-seeking bees with higher abundance, B. lepidus and B. friseanus, the peak abundance was obviously staggered. In addition, the colony cycle of B. lepidus was shorter than B. friseanus (Fig. 1). Goulson and Darvill (2004) suggested that to avoid strong competition for limited resources, some rare bee 
species might have short colony cycles in order to coexist with the common species by specializing on shortlived high-quality resources to rear larvae quickly. The staggered emergence time may help to contribute to the coexistence of the bees.

Although the study meadow provided a large variety of flowering plants, the plants chosen for foraging did not vary significantly among all the species pairs of bees in the two years. It has been suggested that plant preference of a bee may change spatially and temporally (Jha \& Kremen, 2013; Miller-Struttmann \& Galen, 2014). We did not find niche differentiation in proboscis length or flower use in this meadow. Additionally, bumble bees may have intrinsic preferences for reward type (pollen vs. nectar) (Roulston \& Cane, 2000). Niche differentiation in proboscis length and flower use may not occur if bees only rarely, if ever, seek nectar. On the other hand, our results indicated that plant preference obviously varied across the flowering period of the meadow. For the two mainly nectar-seeking bees, niche differentiation in proboscis length and flower use was not detected by analyzing the collective data of a year. It might exist in a complicated way and depend on community spatial and temporal factors, which allow the bees to adjust their foraging strategy in response to changes in availability of floral resources.

\section{The influence of intensity of interspecific competition on foraging strategy for the three bees}

Our study indicated that the intensity of interspecific competition (estimated by niche overlap) was not correlated with bee abundance across the sampling dates. The increasing bee abundance did not accelerate the intensity of interspecific competition while the mitigation of intensity of interspecific competition was not caused by a decrease of bee abundance. Moreover, we found that the foraging strategy was significantly correlated with competition intensity for all the three bees (Figs. 3 and 4). We conclude that for these bumble bees, the primary factor influencing the temporal change of foraging strategy might be the abundance of interspecific instead of intraspecific individuals.

The mainly pollen-seeking bee, $B$. festivus, foraged more on nectarless flowers than those with nectar during our investigations. However, its preference for reward type (pollen vs. nectar) did not remain stable. Our results indicated that the intensity of interspecific competition significantly influenced the foraging strategy of the bee. The bee mainly visited nectarless flowers to collect pollen grains on the days with low competition intensity. As competition intensity increased, the bees tended to forage for nectar. Although pollen provides important and necessary nutrimental requirement for bumble bee (Roulston \& Cane, 2000; Goulson \& Darvill, 2004; Woodard, 2017; Woodard et al., 2019), nectar may provide more energy than pollen (Baker \& Baker, 1983). The increase of intensity of interspecific competition may decrease the availability of floral rewards, which may also reduce the net energy intake for a single foraging trip. In this circumstance, a shift to foraging for nectar may benefit colony development.

Although we did not detect niche differentiation in proboscis length and flower use for the two mainly nectar-seeking bumble bees (B. lepidus and B. friseanus), because they foraged on a wide range of flowering plants, the application of the index of composite flower depth uncovered that such niche differentiation might occur. The fact that the ratios of worker proboscis length for the species pairs are 1.18 (festivus :friseanus ) and 1.25 (friseanus :lepidus), close to the ratio of 1.2 predicted as a minimum for coexisting species (Inouye, 1978), suggests that proboscis length might play some role in the resource partitioning. When the intensity of interspecific competition was low, the flowers chosen by $B$. friseanus presented a larger composite flower depth than those visited by B. lepidus, the bee with relatively shorter proboscis length (Fig. 4). The individuals of $B$. lepidus had a much longer proboscis length than the composite flower depth of the plants they visited. Although long-tubed flowers may prevent a short-proboscid pollinator from removing nectar (unless they resort to nectar robbing), long-proboscid pollinators may retain the option of visiting shorttubed flowers for nectar (Nilsson, 1988; Johnson et al., 2017; Vlašánková et al., 2017). Our study suggests that the match of proboscis length and flower depth may not be important in the niche differentiation in proboscis length and flower use at our study site.

However, the bees' foraging preferences were significantly influenced by intensity of interspecific competition. As the competition intensity increased, B. friseanus, the bee with relatively longer proboscis, shifted to visit 
plants with shorter flower depth, and the bees with shorter proboscis (B. lepidus) tended to visit plants with longer flower depth. When the competition intensity reached its highest point, the ratio of the composite flower depth to proboscis length was in the range of 0.5 to 0.6 for both the two bees. However, the plant assemblages visited by the two bees were still highly variable except for the most dominant plant, Polygonum macrophyllum (Table S3). When the competitor bee species reduced the availability of floral resources, enhancement of foraging efficiency in terms of net energy intake would be important for the coexisting bees. The match of proboscis length and flower depth might highly enhance the foraging efficiency, e.g. reducing the handling time on a flower (Inouye, 1980; Ranta \& Lundberg, 1980). The temporal dynamic in plant preference for the two mainly nectar-seeking bees in response to competition intensity contributed to our understanding of niche differentiation in proboscis length and flower use.

In conclusion, our study indicated that the community context of foraging strategy for bumble bees not only responded to intensity of interspecific competition, but also depended on preference for reward type (pollen vs. nectar). Moreover, the change of foraging strategy in response to competition intensity depended on the species. For the mainly pollen-seeking bee, B. festivus, when the intensity of competition with the other two bees (B. friseanus and B. lepidus ) increased, it was forced to adjust its foraging preference between plants with and without nectar but not to change to target plants with different flower depths. At relatively high abundance, the latter two species did not respond to intensity of competition withB. festivus at all. The two bees mainly sought nectar, and an increase in competition intensity impelled them to shift their flower preferences to enhance the foraging efficiency. Our findings suggest that in a community, intensity of interspecific competition, relative bee abundance, and reward preference (pollen vs. nectar) might collectively influence the niche differentiation in flower use for a bumble bee species. The coexistence of multiple bumble bee species in a community should be achieved by adjusting foraging strategy in response to intensity of interspecific competition for floral resources.

Acknowledgements We thank Min Lv, De-Xin Liu, Yong-Deng He, Si-Zhen Liu and Yi-Fan Ma for field assistance and Yan-Hui Zhao and Huan Liang for helping in insect identification. This work was supported by the National Natural Science Foundation of China (Nos. 31970253 and 31770255 to CFY, 31800194 to ZMY).

\section{References}

Baker, H. G., \& Baker, I. (1983). A brief historical review of the chemistry of floral nectar, pp. 126-152. In Bentley, B., \& Elias, T. (eds.), The Biology of Nectaries. Columbia University Press, New York.

Colwell, R. K., \& Futuyma, D. J. (1971). On the measurement of niche breadth and overlap. Ecology, 52, $567-576$.

Garratt, M. P. D., Coston, D. J., Truslove, C. L., Lappage, M. G., Polce, C., Dean, R., ... Potts, S. G. (2014). The identity of crop pollinators helps target conservation for improved ecosystem services. Biological Conservation, 169, 128-135.

Goulson, D., \& Darvill, B. (2004). Niche overlap and diet breadth in bumblebees; are rare species more specialized in their choice of flowers? Apidologie, 35, 55-63.

Goulson, D., Hanley, M. E., Darvill, B., Ellis, J. S., \& Knight, M. E. (2005). Causes of rarity in bumblebees. Biological Conservation, 122, 1-8.

Goulson, D., Lye, G. C., \& Darvill, B. (2008a). Decline and conservation of bumble bees. Annual Review of Entomology, 53, 191-208.

Goulson, D., Lye, G. C., \& Darvill, B. (2008b). Diet breadth, coexistence and rarity in bumblebees. Biodiversity and Conservation, 17, 3269-3288.

Goulson, D., Nicholls, E., Botias, C., \& Rotheray, E. L. (2015). Bee declines driven by combined stress from parasites, pesticides, and lack of flowers. Science, 347, 1432-1437. 
Hanley, M. E., Franco, M., Pichon, S., Darvill, B., \& Goulson, D. (2008). Breeding system, pollinator choice and variation in pollen quality in British herbaceous plants. Functional Ecology, 22, 592-598.

Hegland, S. J., \& Totland, Ø. (2008). Is the magnitude of pollen limitation in a plant community affected by pollinator visitation and plant species specialization levels? Oikos, 117, 883-891.

Heinrich, B. (1976). Resource partitioning among some eusocial insects: Bumblebees. Ecology, 57, 874-889.

Huang, J. X., Wu, J., An, J. D., \& Williams, P. (2015). Newly discovered colour pattern polymorphism of Bombus koreanus females (Hymenoptera: Apidae) demonstrated by DNA barcoding. Apidologie, 46, 250-261.

IBM Corp. Released 2013. IBM SPSS Statistics for Windows, Version 22.0. Armonk, NY: IBM Corp.

Inouye, D. W. (1977). Species structure of bumblebee communities in North America and Europe, pp. 35-40. In Mattson W. J. (ed.), The role of arthropods in forest ecosystems. Springer, New York.

Inouye, D. W. (1978). Resource partitioning in bumblebees: experimental studies of foraging behavior. Ecology, 59, 672-678.

Inouye, D. W. (1980). The effect of proboscis and corolla tube lengths on patterns and rates of flower visitation by bumblebees. Oecologia, 45, 197-201.

Ishii, H. S., Kadoya, T., Kikuchi, R., Suda, S. I., \& Washitani, I. (2008). Habitat and flower resource partitioning between exotic and native bumble bees: result of the competitive interactions. Biological Conservation, $141,2597-2607$.

Jha, S., \& Kremen, C. (2013). Resource diversity and landscape-level homogeneity drive native bee foraging. Proceedings of the National Academy of Sciences of the United States of America, 110, 555-558.

Johnson, S. D., Moré, M., Amorim, F. W., Haber, W. A., Frankie, G. W., Stanley, D. A., .. Raguso, R. A. (2017). The long and the short of it: a global analysis of hawkmoth pollination niches and interaction networks. Functional Ecology, 31, 101-115.

Konzmann, S., \& Lunau, K. (2014). Divergent rules for pollen and nectar foraging bumblebees - a laboratory study with artificial flowers offering diluted nectar substitute and pollen surrogate. PLoS One, 9: e91900.

Miller-Struttmann, N. E., \& Galen, C. (2014). High-altitude multi-taskers: bumble bee food plant use broadens along an altitudinal productivity gradient. Oecologia, 176, 1033-1045.

Moerman R, Roger N, De Jonghe R, Michez D, Vanderplanck M. 2016. Interspecific variation in bumblebee performance on pollen diet: New insights for mitigation strategies. PLoS ONE 11: e0168462.

Nilsson, L. A. 1988. The evolution of flowers with deep corolla tubes. Nature, 334, 147-149.

Nishikawa, Y., \& Shimamura, T. (2016). Effects of alien invasion byBombus terrestris L. (Apidae) on the visitation patterns of native bumblebees in coastal plants in northern Japan. Journal of Insect Conservation, $20,71-84$.

Ogilvie, J. E., Griffin, S. R., Gezon, Z. J., Inouye, B. D., Underwood, N., Inouye, D. W., \& Irwin, R. E. (2017). Interannual bumble bee abundance is driven by indirect climate effects on floral resource phenology. Ecology Letters, 20, 1507-1515.

Pyke, G. H. (1982). Local geographic distributions of bumblebees near Gothic, Colorado: competition and community structure. Ecology, 63, 555-573.

Pyke, G. H., Inouye, D. W., \& Thomson, J. D. (2012). Local geographic distributions of bumble bees near Crested Butte, Colorado: competition and community structure revisited. Environmental Entomology, 41, 1332-49.

Ranta, E., \& Lundberg, H. (1980). Resource partitioning in bumblebees- The significance of differences in proboscis length. Oikos, 35, 298-302. 
Ranta, E., \& Vepsalainen, K. (1981). Why are there so many species? Spatio-temporal heterogeneity and northern bumblebee communities. Oikos, 36, 28-34.

Ranta, E., Lundberg, H., \& Terns, I. (1981). Patterns of resource utilization in two Fennoscandian bumblebee communities. Oikos, 36, 1-11.

Ranta, E. (1982). Species structure of north European bumblebee communities. Oikos, 38, 202-209.

Ranta, E., \& M. Tiainen. 1982. Structure in seven bumblebee communities in eastern Finland in relation to resource availability. Holarctic Ecology. 5, 48-54.

Ranta, E. (1984). Proboscis length and the coexistence of bumblebee species. Oikos, 43, 189-196.

Roger N, Michez D, Wattiez R, Sheridan C, Vanderplanck M. 2017. Diet effects on bumblebee health. Journal of Insect Physiology 96: 128-133.

Roulston, T. H., \& Cane, J. H. (2000). Pollen nutritional content and digestibility for animals. Plant Systematics and Evolution, 222, 187-209.

Roulston, T. H., \& Goodell, K. (2011). The role of resources and risks in regulating wild bee populations. Annual Review of Entomology, 56, 293-312.

Schoener, T. W. 1974. Resource partitioning in ecological communities. Science, 185, 27-39.

Thomson, D. M. (2016). Local bumble bee decline linked to recovery of honey bees, drought effects on floral resources. Ecology Letters, 19, 1247-1255.

Vaudo, A. D., Patch, H. M., Mortensen, D. A., Tooker, J. F., \& Grozinger, C. M. (2016). Macronutrient ratios in pollen shape bumble bee (Bombus impatiens) foraging strategies and floral preferences. Proceedings of the National Academy of Sciences of the United States of America, E4035-E4042.

Vlašánková, A., Padyšáková, E., Bartoš, M., Mengual, X., Janečková, P., \& Janeček, Š. (2017). The nectar spur is not only a simple specialization for long-proboscid pollinators. New Phytologist, 215, 1574-1581.

Williams, P. H. (1989). Why are there so many species of bumblebees at Dungeness? Botanical Journal of the Linnean Society, 101, 31-44.

Williams, P. H., \& Osborne, J. L. (2009). Bumblebee vulnerability and conservation world-wide. Apidologie, 40 (3), 367-387.

Williams, P., Colla, S., \& Xie, Z. (2009). Bumblebee vulnerability: common correlates of winners and losers across three continents. Conservation Biology, 23, 931-940.

Woodard, S. H. (2017). Bumble bee ecophysiology: integrating the changing environment and the organism. Current Opinion in Insect Science, 20, 101-108.

Woodard, S. H., Duennes, M. A., Watrous, K. M., \& Jha, S. (2019). Diet and nutritional status during early adult life have immediate and persistent effects on queen bumble bees. Conservation Physiology, 7(1), 1-10.

\section{Figure legend}

Fig. 1 . The seasonal abundance of the three most common bumble bee species (Bombus sp.) across sampling dates in 2019.

Fig. 2 . Abundance and the niche overlap of species pairs for the three most common bumble bee species (Bombus sp.).Data from both years are shown. Statistics are shown for the Pearson correlation for each species pair.

Fig. 3 . The relationship of the proportion of nectar collectors out of total visits for Bombus festivus (and its niche overlap to the other two species, B. lepidus $(\mathrm{R}=0.67, \mathrm{P}=0.007)$ and $B$. friseanus $(\mathrm{R}=0.83, \mathrm{P}=$ 0.001), respectively. 
Fig. 4. The relationship between the composite flower depth of plants visited by Bombus lepidus and $B$. friseanus and their niche overlap, respectively.

Table 1. Paired T-test of the composition of flowering plants (identity and the total number of visits) of each of the three most common bumble bee species (Bombus spp., all castes) between species pairs in 2018 and 2019 .

\begin{tabular}{lllllll}
\hline Species pairs & 2018 & 2018 & 2018 & 2019 & 2019 & 2019 \\
\hline & $\mathrm{T}$ & d.f. & $\mathrm{P}$ & $\mathrm{T}$ & d.f. & $\mathrm{P}$ \\
B. festivus vs. B. friseanus & -1.98 & 40 & 0.055 & -1.78 & 41 & 0.083 \\
B. festivus vs. B. lepidus & -2.17 & 40 & $\mathbf{0 . 0 3 6}$ & -0.56 & 41 & 0.58 \\
B. friseanus vs. B. lepidus & -0.78 & 40 & 0.44 & 2.02 & 41 & $\mathbf{0 . 0 5}$ \\
\hline
\end{tabular}

Table 2 . The niche overlap among the three most common bumble bee species (Bombus spp.) across the sampling dates.

\begin{tabular}{llll}
\hline Sampling date & B. festivus vs. B. friseanus & B. festivus vs. B. lepidus & B. friseanus vs. B. lepidus \\
\hline $2018-07-02$ & 0.36 & 0.06 & 0.36 \\
$2018-07-08$ & 0.09 & 0.05 & 0.49 \\
$2018-07-14$ & 0.16 & 0.05 & 0.47 \\
$2018-07-21$ & 0.29 & 0.35 & 0.44 \\
$2018-07-28$ & 0.27 & 0.19 & 0.20 \\
$2019-07-04$ & 0.75 & 0.87 & 0.78 \\
$2019-07-10$ & 0.69 & 0.69 & 0.81 \\
$2019-07-16$ & 0.62 & 0.51 & 0.50 \\
$2019-07-22$ & 0.07 & 0.12 & 0.61 \\
$2019-07-29$ & 0.05 & 0.00 & 0.26 \\
$2019-08-05$ & 0.09 & 0.25 & 0.11 \\
$2019-08-11$ & 0.33 & 0.08 & 0.21 \\
$2019-08-17$ & 0.31 & - & - \\
$2018-08-23$ & 0.31 & - & - \\
$2019-08-529$ & 0.35 & - & - \\
\hline
\end{tabular}

Table 3 . The abundance (average number of visits within a transect), proportion of nectar collectors out of total visits by a bee species (\%) and composite flower depth of plants visited by a bee species for the three most common bumble bee species (Bombusspp., all castes) across the sampling dates.

\begin{tabular}{llll}
\hline Sampling date & Average number of visits within a transect & Average number of visits within a transect & Average number \\
\hline & B. festivus & B. friseanus & B. lepidus \\
$2018-07-02$ & 0.30 & 0.90 & 4.10 \\
$2018-07-08$ & 0.81 & 2.35 & 4.19 \\
$2018-07-14$ & 0.60 & 2.87 & 3.73 \\
$2018-07-21$ & 1.73 & 3.14 & 3.45 \\
$2018-07-28$ & 1.36 & 3.71 & 1.71 \\
$2019-07-04$ & 0.08 & 0.58 & 2.50 \\
$2019-07-10$ & 0.89 & 3.18 & 1.54 \\
$2019-07-16$ & 0.56 & 3.25 & 0.94 \\
$2019-07-22$ & 1.06 & 3.17 & 0.78 \\
$2019-07-29$ & 0.32 & 2.16 & 0.68
\end{tabular}




\begin{tabular}{llll}
\hline Sampling date & Average number of visits within a transect & Average number of visits within a transect & Average number \\
\hline $2019-08-05$ & 0.38 & 1.67 & 0.19 \\
$2019-08-11$ & 0.60 & 1.30 & 0.05 \\
$2019-08-17$ & 0.50 & 1.00 & 0.00 \\
$2018-08-23$ & 0.07 & 1.11 & 0.00 \\
$2019-08-29$ & 0.15 & 0.92 & 0.00 \\
\hline
\end{tabular}

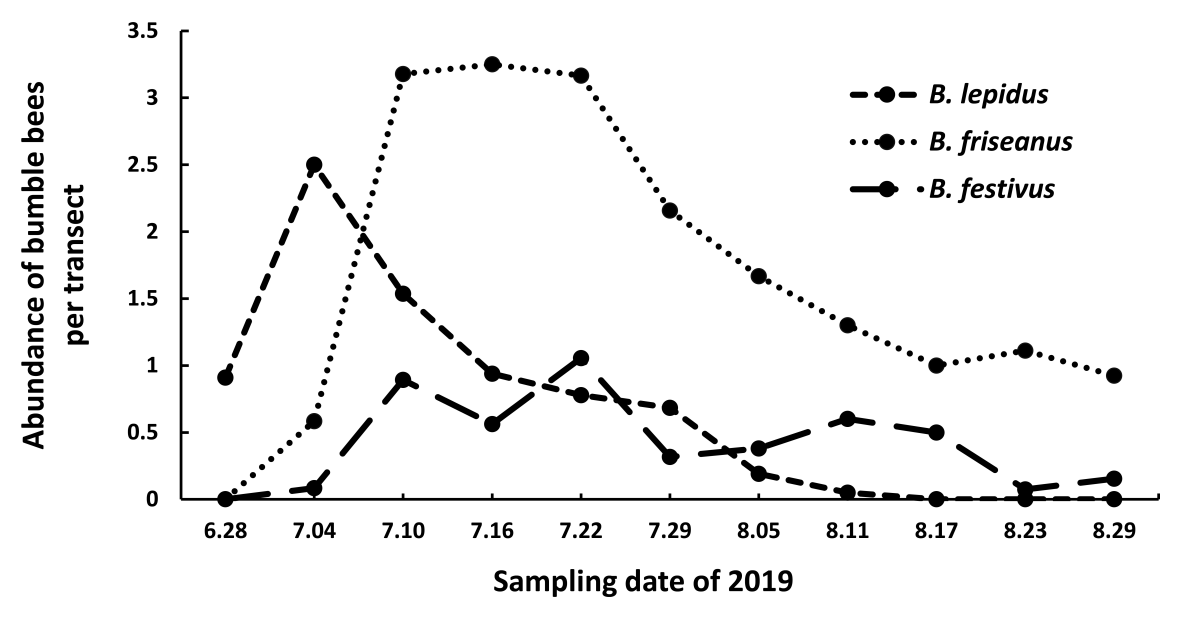



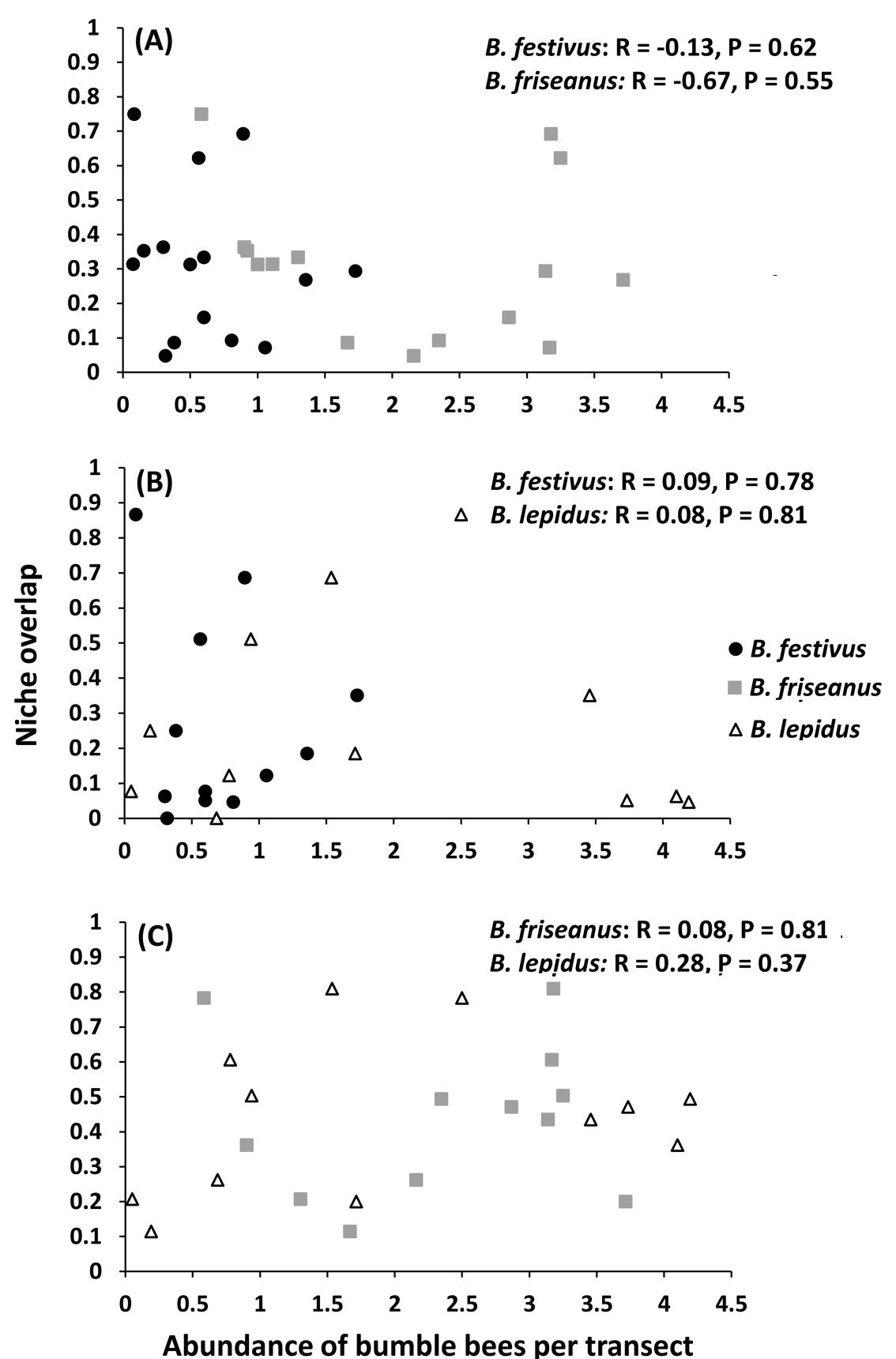

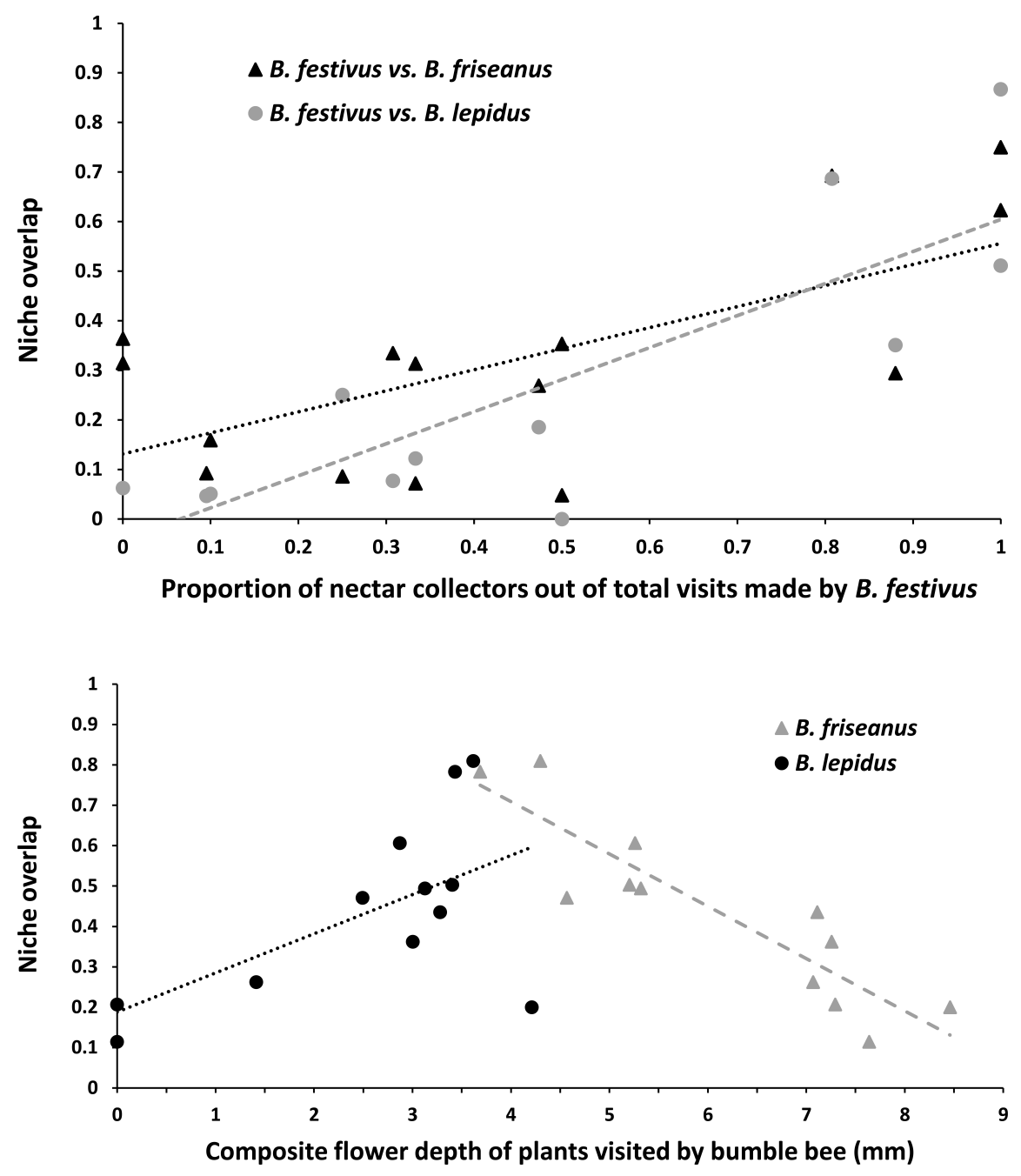